Bol. Acad. peru. leng. 51. 2011 (113-129)

\title{
BIPOLARIDAD, DUALIDAD Y OPOSICIONES EN EL SUEÑO DEL CELTA, DE MARIO VARGAS LLOSA
}

\author{
UNE BIPOLARITÉ, UNE DUALITÉ ET DES OPPOSITIONS \\ DANS LE SOMMEIL DU CELTE, DE MARIO VARGAS LLOSA
}

\author{
BIPOLARITY, DUALITY AND OPPOSITIONS IN THE \\ DREAM OF THE CELT, BY MARIO VARGAS LLOSA
}

\author{
Mercedes Serna \\ Universidad de Barcelona
}

\section{Resumen:}

Vargas Llosa caracteriza la realidad ficticia por lo que denomina su lógica binaria, bipolaridad o juego de oposiciones dobles. Todo lo que existe se duplica en imagen, a menudo paródica o caricatural. Así sucede en El sueño del celta, donde su autor nos muestra las múltiples, contradictorias, ambiguas y delirantes caras de la realidad. La novela toca los temas de la selva, la insurgencia, el nacionalismo, los excesos de poder o los conflictos entre civilización y barbarie o el primitivismo y la modernidad. En este juego de múltiples y opuestas perspectivas, analizaremos, en primer lugar, el que consideramos más importante, esto es, el que atañe a la vida del propio Casement, que fluctúa entre lo real y lo ilusorio, la conciencia ideal y degradada. Asimismo, estudiaremos la contradicción entre lo público y lo privado, las concepciones paradójicas de concebir la colonización, la barbarie, la civilización, la ciudad o el campo. 
Résumé:

Vargas Llosa caractérise la réalité fictive par ce qu'il dénomme sa logique binaire, bipolarité ou jeu de doubles oppositions. Tout ce qui existe se double dans une image, souvent parodique ou caricatural. Ainsi se déroule dans Le rêve du Celte, où son auteur nous montre les multiples visages, contradictoires, ambigus et délirants, de la réalité. Le roman touche les sujets de la forêt, de l'insurgence, du nationalisme, les excès de pouvoir ou les conflits entre civilisation et barbarie ou le primitivisme et la modernité. Dans ce jeu de perspectives opposées et multiples, nous analyserons, en premier lieu, celui que nous considérons le plus important et qui concerne la vie du propre Cassement qui fluctue entre le réel et l'illusoire, la conscience idéale et dégradée. De la même manière nous étudierons la contradiction entre le public et le privé, les conceptions paradoxales de concevoir la colonisation, la barbarie, la civilisation, la ville ou le champ.

\section{Abstract:}

Vargas Llosa distinguishes the fictitious reality for what he names binary logic, bipolarity or game of double examinations. Everything that exists doubles in image, often as parody or caricature. This happens in "The dream of the Celt", where his author shows us the multiple, contradictory, ambiguous and delirious faces of reality. The novel touches the topics of the jungle, the insurgency, the nationalism, the excesses of power or the conflicts between civilization and barbarism or the primitivism and the modernity. In this game of multiple and opposite perspectives, we will analyze, first, the one that we consider to be the most important, this is, the fact that it concerns the life of the own Casement, which fluctuates between the reality and illusion, the ideal conscience and the degraded one. Likewise we will study the contradiction between the public and the private, the paradoxical conceptions of conceiving the colonization, the barbarism, the civilization, the city or the field.

Palabras clave:

Colonización; oposiciones; dualidades; trasgresión; eurocentrismo. 
Mots clés:

Colonisation; oppositions; dualités; transgression; eurocentrisme.

Key words:

Colonization; oppositions; dualities; transgression; eurocentrism.

Fecha de recepción:

$23 / 12 / 2010$

Fecha de aceptación:

$25 / 02 / 2011$

En El sueño del celta, como en toda su última etapa novelística, que podemos encuadrar dentro de la "nueva narrativa histórica", Vargas Llosa renuncia a las técnicas literarias más novedosas, cuyo dominio y virtuosismo puso de manifiesto en su primera etapa literaria. Esto no quiere decir, sin embargo, que Vargas Llosa haya regresado al realismo ingenuo de la etapa anterior sino, más bien, que, desencantado por cierto extravío literario que cayó en el mero virtuosismo, así como en la prescindencia de la realidad, ha decidido seguir trascendiendo el realismo ingenuo por otras vías, quizás menos llamativas desde el punto formal, pero, ciertamente, más interesantes desde el punto de vista filosófico.

Es normal, pues, que en El sueño del celta, el autor sea parco en la utilización de recursos típicos de la técnica cinematográfica (camera eye, flashback, travelling, close-up), no concentrará tiempo y espacios, ni los entrecruza, ni superpone diálogos que pertenecen a tiempos diferentes. Tampoco trabajará con el procedimiento pluridimensional: fusión de la realidad objetiva, el diálogo, y los movimientos irracionales de la subjetividad. La complejidad de la obra, por tanto, no vendrá por la experimentación en las técnicas literarias, más propias de la narrativa de los setenta. Como decíamos, Vargas Llosa trasciende el texto realista, el realismo ingenuo sin apelar tanto a los recursos formales (como en novelas anteriores) como a las ideas y al contenido (como hace Borges) y eso lo efectuará recurriendo a la bipolaridad..." o "recurriendo a técnicas y reflexiones literarias que den cuenta del carácter dual de la realidad". 
En esta novela, el narrador nos cuenta, en tercera persona, la historia de Casement, un diplomático irlandés y defensor de los derechos humanos, cuya misión será denunciar el genocidio perpetrado por la autoridad de Leopoldo II y las compañías comerciales belgas en el Congo, a finales del siglo XIX, y las atrocidades cometidas contra los indígenas, por la compañía inglesa de Julio C. Arana, La Peruvian Amazon Company, en el Putumayo.

La novela se inicia in media res, con Casement ya en la prisión, en 1919, en Londres, acusado de traición a la patria, por su exacerbado nacionalismo irlandés. En el segundo capítulo, en un salto temporal, el narrador, utilizando la técnica de flashback, nos trasladará al momento del nacimiento de Casement, en 1864. A partir de este punto, Vargas Llosa irá alternando la narración de su vida, que incluye su estancia en el Congo, en la Amazonía, Brasil o Europa, con la de su estancia en la cárcel londinense. Es la crónica de una ejecución anunciada.

En la primera parte se narran las actividades de Casement en el Congo Belga, en 1903, que se habría desplazado a esta zona con el fin de verificar qué había de cierto sobre las acusaciones de iniquidades contra indígenas, en las zonas caucheras, que habían lanzado ciertas iglesias y Edmund D. Morel, periodista que había llamado la atención acerca de la situación crítica que se estaba viviendo en la zona.

Tras una temporada en el Brasil, entre 1906 y 1919, la segunda historia de relieve es la de Casement en la Amazonía, con el fin de investigar las atrocidades cometidas por los caucheros, en 1910. Vargas Llosa logra conectar dos espacios de colonización, de modo que la novela es también un experimento mental de autocomprensión latinoamericana. Además, puede explotar un imaginario que ya fue tratado en La Vorágine y que él mismo trató en La casa verde. Por así decirlo, este viaje de Casement a la Amazonía es el eje que relaciona América y África.

Otros espacios nos llevarán a Europa, especialmente a Gran Bretaña e Irlanda. Entre estos espacios se narrará la tercera historia, la de la conversión del protagonista al nacionalismo radical, lo que le llevará 
incluso a comparar la colonización de los europeos en el Congo o en la Amazonía, a la sufrida por Irlanda bajo el poder de Gran Bretaña. "Los métodos de la colonización en Europa son más refinados, pero no menos crueles" (Vargas Llosa: 2010, 389), afirmará Casement. El propio protagonista se cuestionará si su lucha por la independencia de Irlanda no le estará convirtiendo en un fanático, duda que no resuelve tampoco el lector, a tenor de las conflictivas relaciones entre Gran Bretaña y su vecino invadido y expoliado.

Vargas Llosa ha proyectado en la misión de Casement algunas experiencias personales, por cuanto fue nombrado para liderar la comisión investigadora de los periodistas en Uchuraccay. Existe un claro paralelismo entre el autor de El sueño del celta y el autor del Informe sobre el Putumayo.

Todas las historias tienen como tema principal el colonialismo, el que ejercen los europeos en la Amazonía, en el Congo Belga y el de los europeos sobre otros países europeos, como Inglaterra en Irlanda. Paradójicamente, el protagonista, Casement, no morirá en la supuesta barbarie, sea la Amazonía o el Congo, sino a manos de los presuntos civilizados, de los ingleses. Este hecho nos recuerda al ensayo "Los caníbales" de Montaigne y la idea de que hay una barbarie civilizada y una civilización bárbara. Recordemos cómo Montaigne, tras conversar con tres caníbales que habían llevado a Francia, llegará a afirmar que todo lo dicho en nada se asemeja a la insensatez ni a la barbarie y que lo que hay es que estas gentes no gastan calzones ni coletos (Montaigne: 2003, 263-278)

Para no caer en el mero juicio de valor, el autor reflexiona acerca de la diversidad de formas que adoptó el colonialismo a lo largo del tiempo y del espacio. Pero no adopta un tono prescriptivo sino meramente descriptivo. Muestra, no juzga. Narra, no moraliza. La diversidad geográfica sirve para plantear la naturaleza del colonialismo, si sus formas de actuación son distintas dependiendo del país colonizado y de quién sea el sujeto que coloniza, o, si, por el contrario, el colonialismo, venga de donde venga, se comporta de idéntica manera. 
Novela de múltiples perspectivas, El sueño del celta toca los temas de la selva, la insurgencia, el conflicto entre civilización y barbarie, el nacionalismo, el primitivismo y la modernidad o los excesos de poder. En esta novela Vargas Llosa proyecta a un escenario mundial un siglo y medio de evolución novelística latinoamericana. Es, por así decirlo, una transfusión literaria de América al mundo o, como diría Pascale Casanova en La República mundial de las letras, una transferencia de capital literario. En este ambiguo juego de perspectivas, la más importante es la que atañe a la vida del propio Casement.

\section{Roger Casement}

La vida de Roger Casement plantea una primera disyunción entre lo público y lo privado. Casement (como Bartolomé de las Casas) es un héroe que denunció los horrores del colonialismo europeo, tanto en el Congo Belga como en la Amazonía, pero también es el autor de unos diarios en los que narra supuestas escabrosas aventuras sexuales. ¿Cómo puede ser que la vida de un hombre heroico e intachable quede manchada por un acto, en este caso, privado y personal? ¿Puede la historia borrar, tal como señala la novela, "los sacrificios de esos veinte años africanos, los siete años en América del Sur, el año y pico en el corazón de las selvas amazónicas, el año y medio de soledad, enfermedad y frustraciones en Alemania de Casement por un acto privado y que pertenece al ámbito de la intimidad?" (Vargas Llosa: 2010,136) ¿Puede condenarse a un hombre por un acto? ¿Puede condenarse a Bartolomé de las Casas por su idea de que los negros reemplazaran en los trabajos forzados a los indígenas? Y en el caso de Casement, isu diario sexual, probablemente imaginado, es lo único que quedaría grabado en la memoria histórica?, ¿sólo sus degeneraciones, perversiones o vicios, puede que tan solo imaginados, o quedaría en la memoria del pueblo su lucha en favor de los indígenas?

Tal vez lo mejor de la novela sea cómo Vargas Llosa introduce a lo largo de esta biografía la complejidad del protagonista; su densidad humana, que nace del entrechocar contradictorio e imposible de enjuiciar de todos sus actos y significaciones. Casement es un héroe con múltiples matices, alejado de los héroes épicos, de los héroes estándar, 
más allá de todo estereotipo. No hay un yo fijo, coherente e inmutable, sino una construcción gradual y cultural, que ofrece diversas caras, imposibles de conocer de manera definitiva. Como señala el propio Vargas Llosa en el epílogo de la novela, "un héroe y un mártir no es un prototipo abstracto ni un dechado de perfecciones sino un ser humano, hecho de contradicciones y contrastes, debilidades y grandezas" (Vargas Llosa: 2010, 448)

Casement es hijo de su educación puritana, de costumbres rígidas, tradicionales y conservadoras, que habían reprimido cualquier amago de excitación (Vargas Llosa: 2010, 280). Y es que en las novelas de Vargas Llosa el orden, necesario, está para transgredirlo. De esta manera, al igual que ocurría en La casa verde, y como analizó en su día José Miguel Oviedo, aparece aquí también el binomio orden y trasgresión. El orden (social, político, moral, legal) aparece siempre cuestionado, amenazado.

En la visión de Vargas Llosa, el orden limita la libertad y el impulso vital. La trasgresión es la manifestación de este impulso vital: este es un tema constante en toda su obra y ocupa un puesto central en novelas como La ciudad y los perros, en La casa verde, en Pantaleón y las visitadoras o en El sueño del celta.

Aparece la noción del mal en lo erótico. Vargas Llosa examinaba la noción del mal en Bataille: La paradoja de la vida humana reside en que, para que la vida no cese, la sociedad debe constreñir al hombre, cercarlo de una alambrada de tabúes, obligarlo a sofocar la parte irracional de su personalidad, esa zona espontánea y negativa de su ser que, si fuera dejada en libertad, destruiría el orden, la vida común, instalando en su seno la confusión y la muerte.

La afinidad intelectual con el surrealismo -por su espíritu de rebeldía radical y por su exaltación de lo erótico- es notoria. De todas las figuras del surrealismo, la que más ha marcado a nuestro autor es la de Bataille, novelista, pero, sobre todo, filósofo, teólogo disidente y antirreligioso. Él sostiene que el concepto de lo erótico está necesariamente ligado a la idea de la prohibición: sin prohibición no hay 
sentido del placer, de algo secreto que se viola y destruye gratuitamente. El acto erótico se yergue contra la norma de la prohibición. Hay algo absurdo en ese gesto: es una expresión de vida por ser puro exceso y desperdicio, pero Bataille la asocia a la muerte.

Lo prohibido confiere un valor propio a lo que es objeto de prohibición, lo prohibido da a la acción prohibida un sentido del que antes carecía. Lo prohibido incita a la trasgresión, sin la cual la acción carecería de atracción maligna y seductora. Lo que seduce, tal como se dice en Las lágrimas de Eros, es la trasgresión de lo prohibido.

Esta idea de lo maldito está en las obras de Vargas Llosa, en las asociaciones, por ejemplo, que hace entre el cuartel y el burdel, en Pantaleón y las visitadoras, en la corrupción del colegio que se convierte en burdo cuartel, en La ciudad y los perros, en las asociaciones entre el convento y el burdel de La casa verde o en las de dictadura y prostíbulo en Conversación en la catedral o La fiesta del chivo.

Ya la poesía de Darío se anticipaba al pensamiento de la época al plantear, en El coloquio de los centauros -diálogo filosófico que expresa el sentido religioso del universo y la vida regidos por el amor y la muerteel tema de la simbiosis entre la bestia y el hombre. La preocupación por descubrir el reverso del hombre se reflejaba, asimismo, en Dr Jekyll y $\mathrm{Mr}$ Hyde, de Robert Louis Stevenson, especie de atractivo que conduce a la literatura del mal, en la tradicional imagen del ángel y la bestia. El papel de las zonas oscuras, consideradas pecaminosas, con el modernismo, adquirirán un gran protagonismo.

"Yo comprendo el secreto de la bestia" (Darío: 1991, 71) exclamará el verso dariano, es decir, yo entiendo las raíces del mal. La capacidad de entroncar el bien y el mal será, en estos versos helénicos, un triunfo. La poesía de Darío es expresión de su dualidad humana, la lucha entre sus tendencias impulsivas y las represiones determinadas por la educación social y religiosa. El carácter enigmático de la realidad consiste en que cada forma es doble o triple y cada ser es reminiscencia y prefiguración de otro. Los monstruos ocupan un lugar privilegiado en este 
mundo. Son los símbolos de la dualidad. Como señala Paz, "la filosofía de Darío se resuelve en esta paradoja: saber ser lo que sois, enigmas siendo formas".(Paz: 1991, 40).

Pero Casement no sólo es sujeto de una escisión sincrónica, sino también diacrónica. Es muchos seres en el ahora y en el tiempo: si de joven se nos presenta como un probritánico, siguiendo la estela de su padre, de mayor se convertirá en un nacionalista irlandés. Casement, que aprobaba en su juventud la pena de muerte, ahora, luego, en tanto espera que le sea condonada la suya, no puede pensar de igual manera. Si en su juventud, concibe la colonización como una herramienta de modernización, tras lo vivido en los países colonizados, llegará a la conclusión de que la colonización ha llevado la desgracia y la barbarie a esos territorios: "Había visto mundo, su horizonte se amplió enormemente, entendió mejor la vida, la realidad humana, la entraña del colonialismo, la tragedia de tantos pueblos por culpa de esa aberración" (Vargas Llosa: 2010, 135).

Casement se mueve entre dos visiones radicalmente opuestas de concebir el mundo, entre sus sueños mesiánicos y lo que la realidad le depara; entre el idealismo o las fantasías que se desgajan de sus primeras lecturas de exploradores y que le han configurado un imaginario mítico de África, y su experiencia real de un África degradada y hórrida. ¡Cuántos conquistadores fueron a hacer las Américas ante visiones míticas surgidas de las lecturas de las crónicas de Indias! Como señalaba en su día Edward W. Said, la actitud textual atenúa el carácter amenazante e intranquilizador de aquellas realidades hasta entonces desconocidas (Said: 2007, 135). De esta forma, las lecturas configuran un imaginario que influye con mayor fuerza que la propia experiencia real. En Colón, los mitos del buen salvaje y de las islas felices son de origen clásico, y aparecen unidos a la tradición bíblica del redescubrimiento del paraíso terrenal y a las lecturas de Plinio, los viajes de Marco Polo, las leyendas y fantasías bíblicas, clásicas o medievales.

En Casement se dan el villano y el héroe, el traidor y el patriota, el idealista y el realista, la contradicción entre lo público y lo privado. 


\section{Los salvajes y la colonización}

En El sueño del celta, aparecen dos formas confrontadas de ver África. Por un lado se nos presenta como un continente resquebrajado, lugar de atroces vejaciones y sufrimientos, de seres maltratados, cuna de la barbarie y, por el otro, como un lugar donde podían manifestarse las pasiones, fantasías, deseos e instintos y sueños, sin los prejuicios de la vieja Europa (Vargas Llosa: 2010, 281). Como le ocurrió a Gonzalo Guerrero que no sólo se negaría a volver con los españoles sino que lucharía contra sus ejércitos y a la cabeza de las tropas yucatecas, en África también puede ubicarse el paraíso terrenal, donde se da un erotismo envidiado, por desinhibido, y, como señalaba Pedro Mártir, en su Segunda Década, haciéndose eco del mito clásico de la edad de oro donde no hay mío ni tuyo, ni jueces, ni propiedad privada (Mártir de Anglería: 2004, 152)

Asimismo, se ponen en confrontación dos formas opuestas de ver a los indígenas, en un vaivén entre la inocencia y la crueldad. Dos maneras que, a veces, confluyen en un mismo sujeto, que duda sobre la naturaleza de esos seres, y como le ocurrió a Colón, a los cuales describió o como mansos inocentes, o como crueles y animalizados. Tzvetan Todorov señala, al respecto, en La conquista de América, (Todorov, 2005) que Colón nunca sale de sí mismo y nosotros apenas vemos algo que no sean sus proyecciones. Ciertamente, al caracterizar Colón a los indios exclusivamente con adjetivos del tipo bueno/malo, siempre relativos a cada cultura en cuestión, no está diciendo nada de la realidad sino, más bien, sobre sí mismo. Dicha afirmación, vertiginosamente extensible a cualquier otro juicio de valor, nos hace sentir las culturas como inconmensurables, incomparables o injerarquizables. Este hecho que sienta, ciertamente, las bases de una tolerancia radical, por otro lado, deja sin comunicación entre sí a unas culturas que nunca han estado tan incomunicadas como muchos tienden a creer. El misterio está abierto, la caja de Pandora del relativismo es imposible de cerrar, la abrió el contacto constante entre culturas, ejercido fundamentalmente por el colonialismo. 
No son seres humanos, "sino una forma inferior y despreciable de la existencia, más cerca de los animales que de los civilizados" (Vargas Llosa: 2010, 209), señala una voz en El sueño del celta. Palabras que en su origen nos remontan a Aristóteles y su consideración jerárquica de la sociedad humana, que se sustentan en el cronista de la corona Gonzalo Fernández de Oviedo, en el humanista Ginés de Sepúlveda, en Alonso de Zorita, en muchos ilustrados del siglo XVIII, y en Domingo Faustino Sarmiento, influido por la escuela escocesa.

Pero, contrariamente, los indígenas también destacarán por su humanidad y su belleza, la cual se extrapola a la tierra. Dicho contraste ya aparecía con el descubrimiento de América, en la escritura de Cortés o de Bernal Díaz del Castillo, anonadados por la belleza de Tenochtitlan, en Pedro Mártir cuando relata, sin haberla visto jamás, la belleza de Matinino y sus mujeres o en Gonzalo Fernández de Oviedo ante el descubrimiento de la naturaleza americana. Ya en La casa verde se producía una explosión de sensualidad, desorden vital, donde realidad e imaginación se confundían.

En este juego de dualidades y contrastes, también se dan dos formas radicalmente distintas de concebir el colonialismo, uno de los grandes temas de la novela que incluye el de civilización y barbarie; modernidad y primitivismo

¿Qué es civilización?, se pregunta en la novela, a lo cual, otro personaje responde: "Una sociedad donde se respeta la propiedad privada y la libertad individual" (Vargas Llosa: 2010, 207).

La colonización, como creía el joven Casement, en principio, y como creyeron los Reyes Católicos, era una necesidad para el progreso de los colonizados: "Vendrían a ayudarlos a mejorar sus condiciones de vida, librarlos de plagas como la mortífera enfermedad del sueño, educarlos y abrirles los ojos sobre las verdades de este mundo y el otro, gracias a lo cual sus hijos y nietos alcanzarían una vida decente, justa y libre" (Vargas Llosa: 2010, 39). 
Y la colonización, como creyeron los franciscanos, dominicos, los Reyes Católicos, y hasta Bartolomé de las Casas, además, era una obligación moral. De la misma forma, se plantea en El sueño del celta:

¿Y, además, no era bueno para ellos conocer al verdadero Dios, que reemplazaran los ídolos que adoraban por el Dios cristiano, el Dios de la piedad, del amor y de la justicia?...." Era imprescindible que vinieran las buenas cosas del Viejo Continente. No la codicia de los mercaderes de alma sucia, sino la ciencia, las leyes, la educación, los derechos innatos del ser humano, la ética cristiana? (Vargas Llosa:2010, 64).

En pro de la evangelización, la Reina Isabel mandó que los indígenas fueran tratados en calidad de vasallos y no de esclavos; en pro de la evangelización y de un mejor trato hacia los indígenas se firmaron las bulas papales, a las que siguieron las Leyes de Burgos, las Leyes de Valladolid, o las Leyes Nuevas.

Pero, el Requerimiento, las encomiendas, la idea de la guerra justa o el derecho de conquista surgieron bajo la excusa de la evangelización. Esta misma perspectiva aparece cifrada en El sueño del celta. Como señala nuestro protagonista en un momento dado:

Están allí, en sus aldeas, donde han vivido años o siglos. Un buen día llegan unos señores blancos o mestizos con escopetas y revólveres y les exigen abandonar a sus familias, sus cultivos, sus casas, para ir a recoger caucho a decenas o centenas de kilómetros, en beneficio de unos extraños, cuya única razón es la fuerza de que disponen (Vargas Llosa: 2010, 206)

Casi todos los personajes de El sueño del celta aparecen escindidos, golpeados o rotos mental y anímicamente, tras las experiencias vividas, ya sea en el Congo, o en la Amazonía. Tal vez queden indemnes o enteros, sin fisuras, sólo los trapenses, los sacerdotes católicos, los baptistas que conviven con los indígenas y les protegen. En el caso de la Amazonía, por ejemplo, el padre Urrutia, superior de los agustinos de Iquitos, 
exclamará: "Porque los únicos seres que parecían haber conservado su sanidad eran algunos pastores baptistas y algunos misioneros católicos... Unos héroes, la verdad (Vargas Llosa: 2010, 132).

Y, sin embargo, y en una nueva vuelta de tuerca, los trapenses tendrán que transgredir las leyes de los hombres para ser fieles a la ley de Dios, al ayudar a escapar de las garras de los colonos explotadores a siete nativos mutilados. Sin embargo, la paradoja no acaba aquí y los indios llevados a Londres, con el fin de huir de la ignominia y la esclavitud a la que se ven abocados en su continente, desearán, una vez instalados en Europa, volver a su territorio.

Pero el tema de la colonización, en El sueño del celta, no sólo se examina en su representación más conocida, la perpetrada por los europeos sobre otros continentes, sino en la que aquellos ejercen sobre otros territorios de su mismo continente, concretamente, en este caso, la de Inglaterra sobre Irlanda. Al menos, así lo cree el protagonista de El sueño del celta, desde el momento en que, al llegar a la etapa de su vida en la que iba a dedicarse a Irlanda, piensa para sí:

Ahora debía ocuparse de otros indígenas, los de Irlanda. También ellos necesitaban librarse de los "aranas" que los explotaban, aunque con armas más refinadas e hipócritas que las de los caucheros peruanos, colombianos y brasileños" (Vargas Llosa:2010, 378)

Tal vez una de las explicaciones al colonialismo tenga que ver con la afirmación, durante siglos sostenida, de que los europeos provenían de una raza de hombres superiores. Este mito indoeuropeo les llevó a la imposición de sus ideas, en base a esa supuesta superioridad moral intelectual de Occidente sobre el resto del mundo. El eurocentrismo ha permitido que el europeo se haya impuesto sobre el salvaje, -el primitivo o el oriental- y, como señala Josep Fontana, eso ha convertido a los occidentales en cómplices natos de los abusos perpetrados en el resto del mundo, si bien, no hay que olvidar que los abusos de los europeos se han cometido sobre la mayor parte de los propios europeos, a lo largo de su historia (Fontana: 2000,147 ). 
El tema de la colonización nos introduce, asimismo, en la dicotomía ciudad-campo, naturaleza que puede verse también como un contraste histórico, ya que la ciudad es el ámbito de la historia, mientras que la naturaleza es el ámbito de la eterna repetición, de modo que los hombres que viven más cerca de la naturaleza se hallan en un espacio de una temporalidad más lenta o remansada, que siempre queda siglos por detrás de la ciudad, en una especie de no tiempo de repetición "cuasinatural".

En El sueño del celta dicha dicotomía se produce entre la Amazonía e Iquitos, el orden y la ley de Iquitos frente al desorden del Putumayo. En La casa verde, entre Piura y la Misión de Santa María de Nieva había un abismo de distancias, con la masa de los Andes de por medio, de formas de vida, de cultura, de tiempo también. En tanto Piura parece vivir en el siglo X, Santa María oscila entre la edad de piedra y la colonia. Estos dos espacios señalan la gran fragmentación de la sociedad peruana que junta los puntos más bajos y más altos de la escala en una parodia de unidad.

En la novela, sin embargo, y en un nuevo juego de perspectivas, cuando, al final, la compañía de Arana, la Peruvian, se derrumba, y con ello desaparecen el comercio, los barcos o los emigrantes que retornan a Europa, la capital de Loreto, Iquitos, hace un viaje hacia atrás en el tiempo. Como Macondo, Iquitos cae en el olvido, en el aislamiento, tras tres lustros de prosperidad vividos.

En El sueño del celta, todos los valores se tambalean. El rey Leopoldo, escoria, ignominioso, ególatra, aparecerá, bajo los ojos de los países presuntamente civilizados, en calidad de representante del humanitarismo. Conrad, quien reconoció que sin Casement no hubiera podido escribir El corazón de las tinieblas, no firmará el indulto de pena de muerte. Conrad, un gran escritor, es un timorato en asuntos políticos (Vargas Llosa: 2010, 71). Yeats es nacionalista irlandés como Casement pero, pese a ello, no va a ser él sino, paradójicamente, George Bernard Shaw, antinacionalista por escéptico, quien, entre las grandes figuras intelectuales de Londres, se manifieste de manera más explícita y valiente en defensa del protagonista (Vargas Llosa: 2010, 198). 
El sueño del celta permite muchas lecturas, pero claramente en nuestro caso hemos destacado o actualizado tres, una en el plano real (colonialismo europeo), la segunda, en el humano trascendental (la condición humana) y una tercera que es la simbólica y mítica (conceptos como el paraíso o el buen salvaje).

Pero dichas lecturas se interrelacionan de forma compleja haciendo, de esta obra, no tanto una representación, sino un desvelamiento de una realidad olvidada. Vargas Llosa afirmaba en una ocasión: "otra razón para dar a la literatura una plaza importante en la vida de las naciones es que, sin ella, el espíritu crítico, motor del cambio histórico y el mejor valedor de su libertad con que cuentan los pueblos, sufriría una merma irremediable. Porque, como indica Vargas Llosa en La verdad de las mentiras, toda literatura es un cuestionamiento radical del mundo en que vivimos.

Un buen ejemplo lo hallamos en El sueño del celta que descubre lo que la realidad, con sus gobiernos y políticas hipócritas, esconde y calla. 


\section{BIBLIOGRAFÍA}

BATAILLE, G. El erotismo, Barcelona, Tusquets editores, 1979.

CHRZANOWSKI, Joseph. "Mario Vargas Llosa y la interpolaridad vida-ficción", en La historia en la literatura iberoamericana, Memorias del XXIV Congreso del I.I.L.I. Hanover, Eds. del Norte, 1989.

DARÍO, Rubén. Páginas escogidas, edición de Ricardo Gullón, Madrid, Cátedra, 1991.

FONTANA, Josep. Europa ante el espejo, Barcelona, Biblioteca de Bolsillo, 2000.

FRANCO, Jean. "Lectura de Conversación en la Catedral", en Revista Iberoamericana XXXVII, nº 76-77, Pittsburgh, 1971.

FUENTES, Carlos. "El afán totalizante de Vargas Llosa”, en La nueva novela hispanoamericana, México, Joaquín Mortiz, 1969.

GIACOMAN, Helmy y José M. Oviedo. Homenaje a Mario Vargas Llosa, Nueva York, Las Américas, 1972.

LASTRA, Pedro. "Un caso de elaboración narrativa de experiencias concretas en La cuidad y los perros", en Anales de la Universidad de Chile, n 134, Santiago de Chile, 1965.

LOVELUCK, J. ed., Novelistas hispanoamericanos de hoy, Madrid, Taurus, 1974.

MÁRTIR DE ANGlERÍA, P. De Orbe Novo, Alción Editora, estudio preliminar, traducción y notas de Stelio Cro, Córdoba, República Argentina, 2004.

MONTAIGNE, Michel. Ensayos, edición de María Dolores Picazo, Madrid, Cátedra, tres volúmenes, 2003. 
MORENO TURNER, Fernando. Para un análisis de la estructura de 'La Casa Verde', Valparaíso, Universidad de Chile, 1972.

OVIEDO, José Miguel. Mario Vargas Llosa: la invención de una realidad, Barcelona, Barral, 1970.

PAZ, Octavio. Cuadrivio, Madrid, Seix-Barral, 1991.

SAID, E. Orientalismo, Barcelona, De Bolsillo, 2007.

TODOROV, Tzvetan. La conquista de América, Siglo XXI, 2005.

VARGAS LLOSA, Mario. El sueño del celta, Madrid, Alfaguara, 2010. . La verdad de las mentiras, Madrid, Alfaguara, 2002. . "Génesis de La ciudad y los perros", Studi di Litteratura ispano-americana v. III, Milán, 1967-72.

\section{Correspondencia:}

\section{Mercedes Serna}

Profesora titular de literatura hispanoamericana en la Facultad de Filología de la Universidad de Barcelona.

Correo electrónico: serna@ub.edu 